\title{
Plants as Indicators of Soil Types
}

\section{by Keith F. Best and Archie Budd, Swift Current}

For many centuries scientists have studied chemistry, soils, weather, botany, and so on, and endeavoured to correlate their findings to ascertain the best agricultural practices for various areas. In many cases, Nature herself has worked out answers to the problems. The trouble is that we have not as yet fully understood the answers which are given in terms of vegetation of our virgin lands. As Dr. Shantz of the United States Department of Agriculture wrote: "Since plant growth is the ultimate measure of the suitability of the physical environment, the character, growth and condition of the native vegetation are the best possible indicators of conditions, favourable or unfavourable to crop production on lands where crops have not yet been produced."

On sandy soils and dune lands the vegetative indicators are very num-

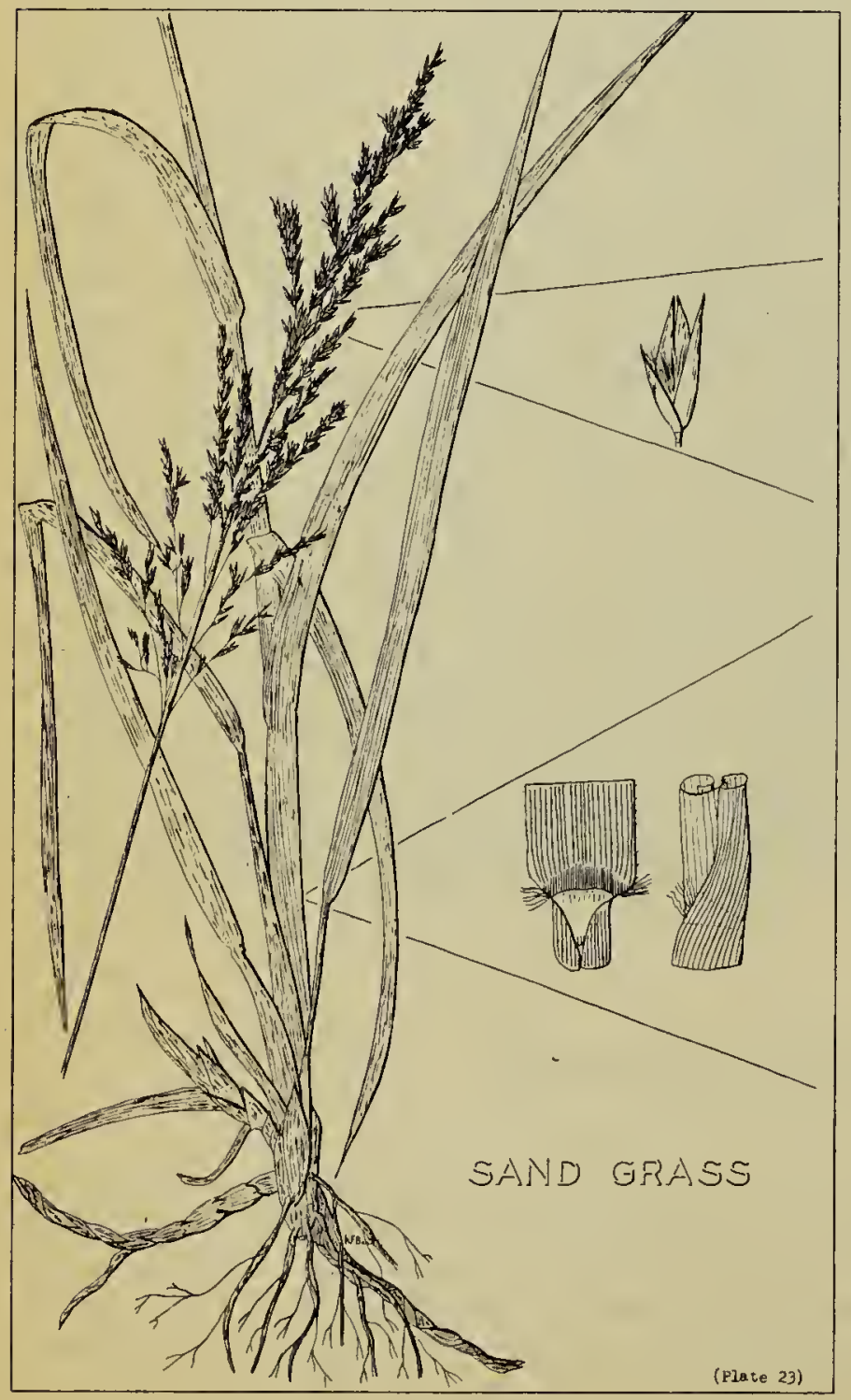

erous. Sand Grass is such a positive indicator that small pockets of sand on loamy hillsides can often be clearly picked out by the patches of tall, yellowish Sand Grass. Sand Dropseed, Nodding Wild Rye and Indian Rice-grass are also positive indicators of very sandy soil and are here discussed.

Sand Grass (Calarnorilfa longifolia) is a tall, coarse species growing to a height of from 3 to 5 feet with feathery flowering panicles of from 6 to 18 inches in length. The leaves are long and generally of a yellowish colour and the stems are very thick and coarse. The creeping rootstocks are thick and scaly and penetrate very deeply into the soil. This enables the grass to thrive where other species would wilt, and to form a good binder for sandy soils.

Sand Dropseed (Sporobolus cryptandrus) is a smaller bunch grass

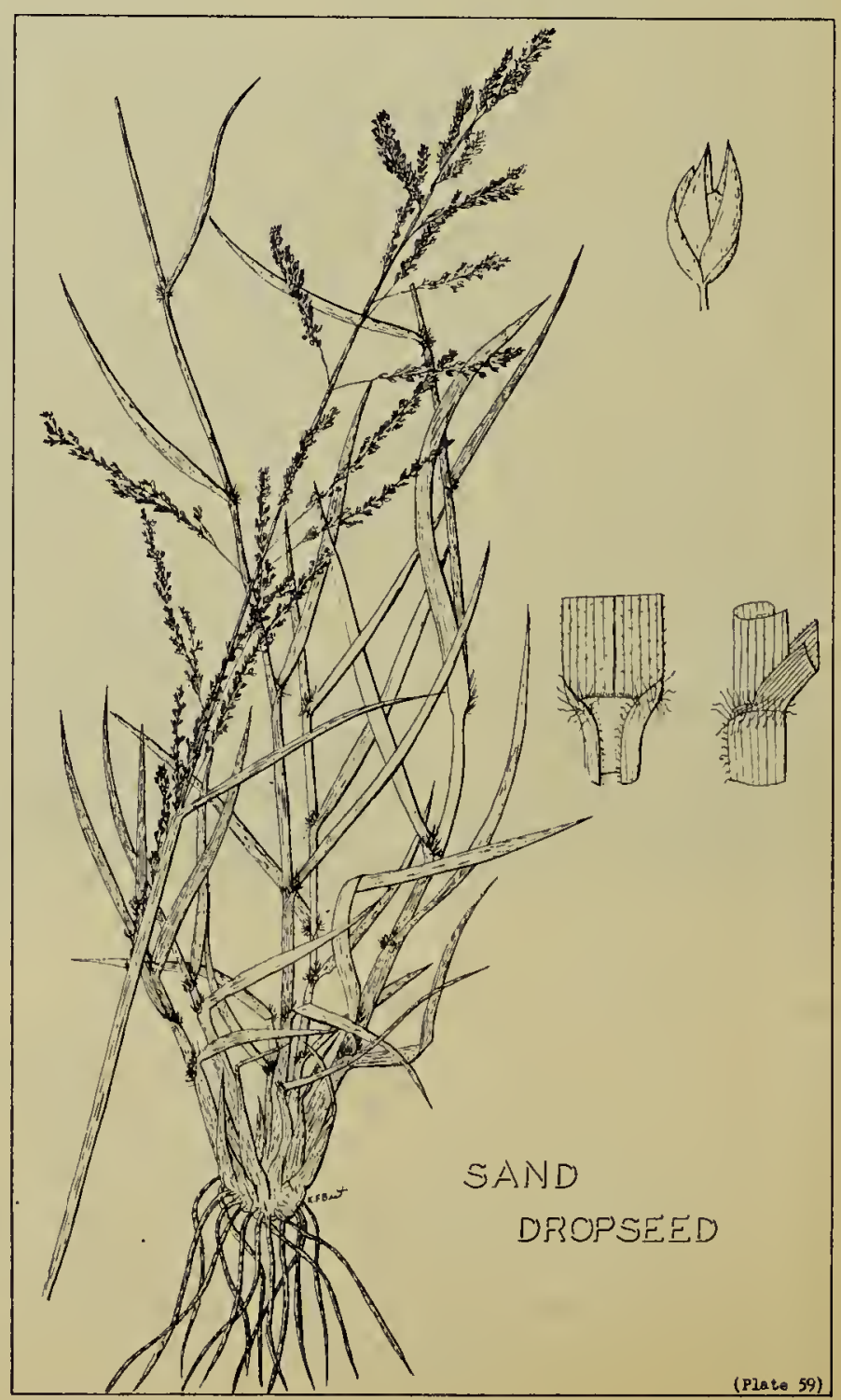




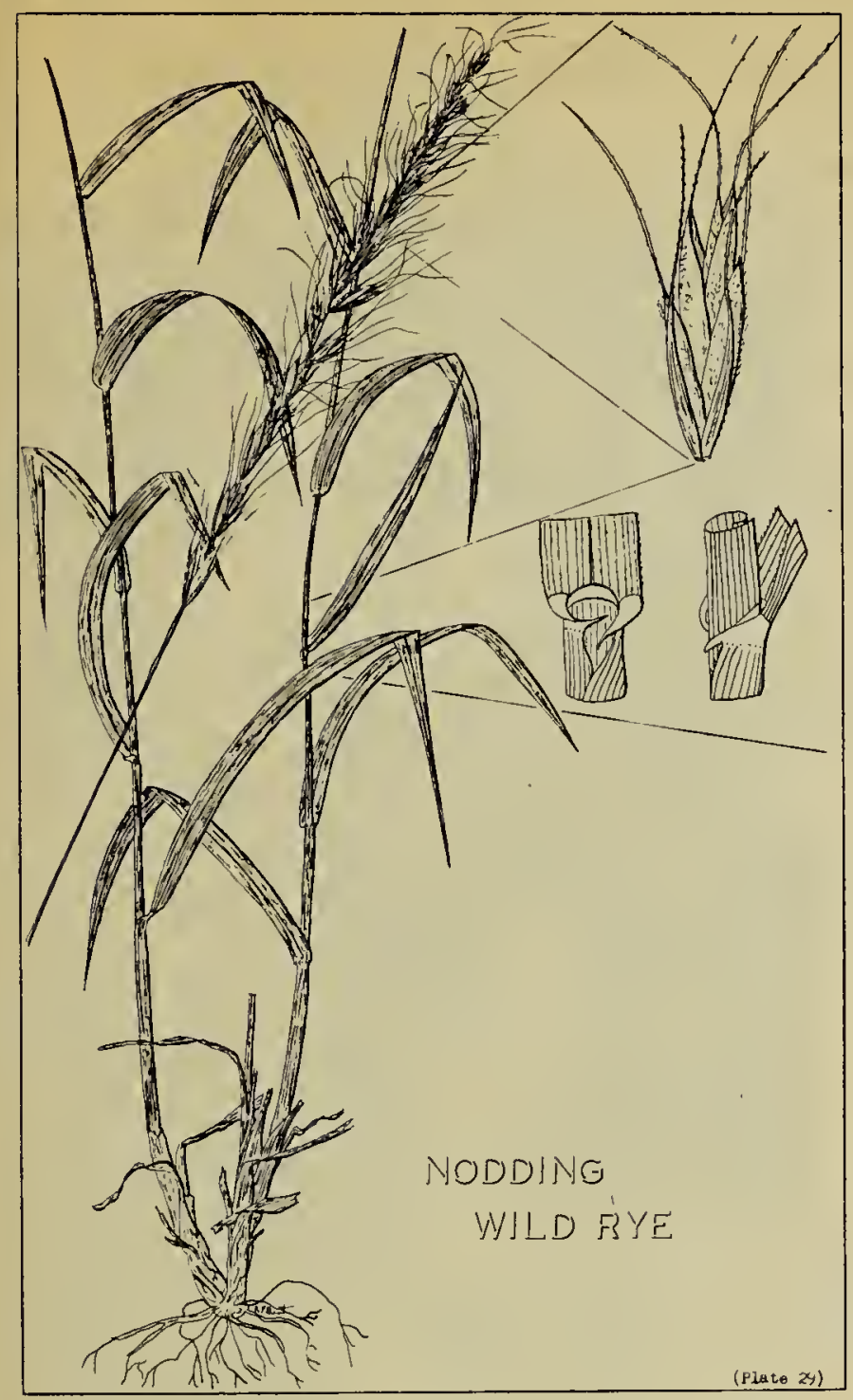

with a deep root system. The leaves generally grow at a very wide angle from the sheath and bear a tuft of hairs at the junction of the sheath and blade, making an easy method of identification in the field. The panicle is often partly enclosed in sheathing leaves until the fruit is almost ready to be shed, giving rise to the specific and also the common name.

There are several species of Elymus or Lyme grasses in the province but Nodding Wild-Rye (Elymus canadensis) is the common indicator of a sandy area. This derives its common name from the flowering heads which are generally drooping or nodding. The plants are a yellowish green colour and the heads are heavily awned and are prolific seeders. It is not very palatable to stock and will be found standing into winter where other species are grazed down, but it is a valuable plant to bind the sandy soils.

Indian Rice-grass (Oryzopsis hymenoides) is probably the most palatable to livestosk of these four sand dune grasses and bears fine,

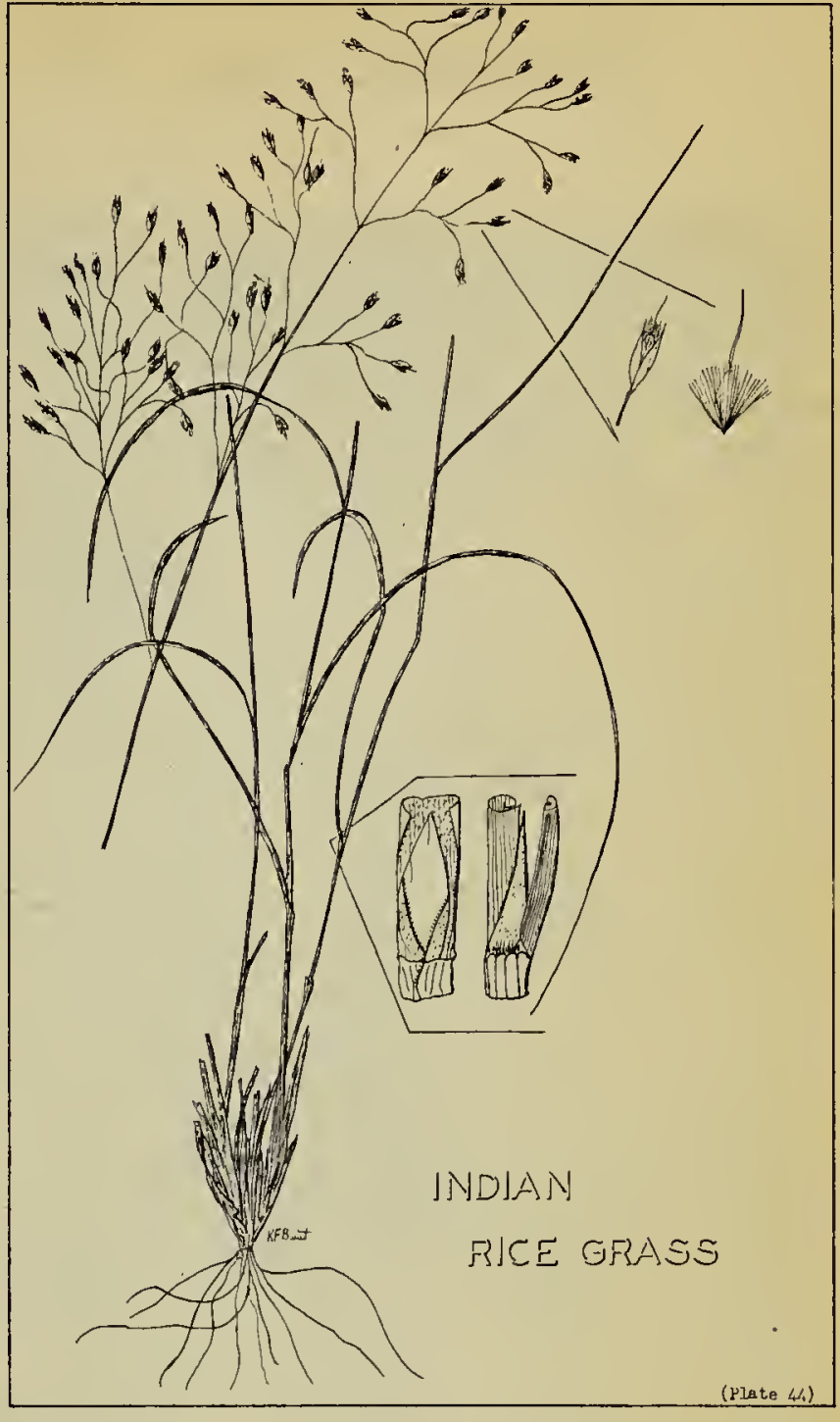

dark green, narrow leaves. The root system is very deep and this is a bunch grass. The inflorescence is a light, feathery panicle with a whitish appearance; there is one flower to each spikelet. The seeds were ground into flour by the Indians. This use of the grass explains its vernacular name.

Where these four grasses are found the soil is definitely too sandy for agricultural use other than grazing.

\section{ATTENTION}

A last-minute request has come from the Department of Natural Resources for information on the status and distribution of the Sage Hen, Centrocercus urophasianus. If you have seen this species during the last five years, send records (if possible with date of observation, locality, number seen, and whether associated with a booming ground) to Mr. Bernard A. Nelson, Wildlife Branch, Government Administration Building, Regina. 